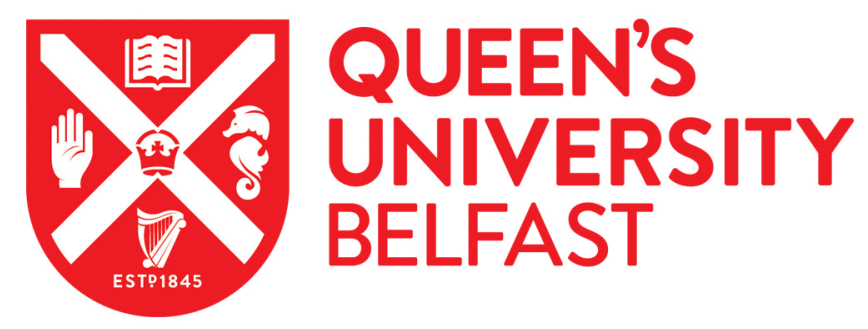

\title{
Promoting contact for children in State care: learning from Northern Ireland on the development of a framework for assessing contact.
}

Devaney, J., \& Wilson, K. (2017). Promoting contact for children in State care: learning from Northern Ireland on the development of a framework for assessing contact. Child Care in Practice, 1-17.

https://doi.org/10.1080/13575279.2017.1406895

Published in:

Child Care in Practice

Document Version:

Publisher's PDF, also known as Version of record

Queen's University Belfast - Research Portal:

Link to publication record in Queen's University Belfast Research Portal

Publisher rights

Copyright 2017 Taylor \& Francis. This work is made available online in accordance with the publisher's policies. Please refer to any applicable terms of use of the publisher.

\section{General rights}

Copyright for the publications made accessible via the Queen's University Belfast Research Portal is retained by the author(s) and / or other copyright owners and it is a condition of accessing these publications that users recognise and abide by the legal requirements associated with these rights.

Take down policy

The Research Portal is Queen's institutional repository that provides access to Queen's research output. Every effort has been made to ensure that content in the Research Portal does not infringe any person's rights, or applicable UK laws. If you discover content in the Research Portal that you believe breaches copyright or violates any law, please contact openaccess@qub.ac.uk. 


\title{
Promoting contact for children in State care: learning from Northern Ireland on the development of a framework for assessing contact.
}

\begin{abstract}
While the principle of contact between children in care and their families is enshrined in law, the precise form and frequency is at the discretion of social workers and the courts. Professionals must seek to balance the twin principles of children's need for protection from the psychological, emotional and physical harm that may arise from having contact with parents and other family members, with the need of family members and children to have their relationships and identity promoted. Courts require clear, structured and unambiguous information about the needs of children and their parents in order make decisions which will have potentially life changing implications for families. In this article we explore one approach to supporting the decision making of legal and social work professionals in relation to the frequency and form of contact by reflecting upon the development by the first author of an approach to assessing the quality and benefits of contact for children in State care in Northern Ireland. We discuss the key principles that should inform decisions and good practice through reflecting on the learning gained from developing and implementing such a structured approach. We conclude that practice has been informed by promoting legal rights without sufficient consideration of the relational aspects of making contact work for each of the involved parties
\end{abstract}

\section{Introduction}

It is estimated that approximately 80,000 children are looked after by the State in the United Kingdom at any moment, although as many as 100,000 children may experience care in any given year. For the purposes of this article a child is deemed to be looked after if they are in the care of a local authority by reason of a court order $(65 \%)$ or through being accommodated in agreement with their parents or carers for a period of more than 24 hours $(27 \%)$. Around one-half of the children who are looked after will experience at least two separate periods of care, and the average length of time that children spend in the care system is increasing (Department for Education, 2016). 
Whilst children become looked after for a variety of reasons, the majority are admitted to care due to a complex interplay of vulnerabilities arising from their needs and their parents' ability to meet these needs (Brophy, 2006). The majority of the 32,000 children who enter state care in England each year become looked after due to abuse and neglect (54\%), family dysfunction (16\%), acute stress within the family $(9 \%)$, the disability of the parent or child $(5 \%)$ or the absence of a parent to provide care (12\%) (Department for Education, 2016). The largest proportion of children enter the care system aged $10-15$ years (29\%), often after a long history of problems and professional involvement, whilst around $61 \%$ of children in the care system entered as a result of a voluntary agreement with their parents (Department for Education, 2016). Each year there are somewhere in the region of 10,000-12,000 applications through the courts for care orders in England, Wales and Northern Ireland. (Cafcass, 2016; NIGALA, 2016).

The National Audit Office (2014) has stated that unless the needs of children in state care are correctly assessed and met effectively, there are significant long-term costs for children, and society, of not getting the right care. Children enter care at varying ages for a wide variety of reasons, and reside in a range of placements, but their primary needs are broadly similar. While much of the research and professional literature has focused on the need for state care to provide children with a sense of stability, security and love (Rees \& Stein, 2016), there is a growing awareness of the need to promote children's sense of identity (Schofield et al., 2017) and pre-existing relationships with parents, siblings and significant others (Larkins et al., 2015).

Contact between children separated from their parents is an area which has received growing attention in recent years (Atwool, 2013). Although it is argued that contact offers clear advantages in many cases to the child and family including in some cases even those children who have previously been abused or neglected by their parents (Neil and Howe, 2004), others are somewhat more cautious and question the benefits in some circumstances (Fratter 1996, Lowe et al., 1999, Loxterkamp 2009). For example, Selwyn (2004) reported that as many as $21 \%$ of children were physically or sexually abused during unsupervised contact with birth family members. 
As noted by Kiraly \& Humphreys (2015), whether parents expect to resume the care of their children or not, there is a strong desire to remain in contact with their offspring. This is mirrored by children, who state that contact with their birth family and close friends is very important for them (Schofield et al., 2017).

While the principle of contact between children in care and their families is enshrined in law, the precise form and frequency is at the discretion of social workers and the courts (Berrick et al., 2015). Professionals must seek to balance the twin principles of children's need for protection from the psychological and emotional harm that may arise from having contact with parents, with the need of family members to have their relationships promoted (Bullen et al., 2015).

In this article we explore one approach to supporting the decision making of legal and social work professionals in relation to the frequency and form of contact by reflecting upon the development by the first author of an approach to assessing the quality and benefits of contact for children in state care in Northern Ireland.

We argue that practice has been informed by promoting legal rights without sufficient consideration of the relational aspects of making contact work for each of the involved parties (Ainsworth \& Hansen, 2017), and the need to have a sound theoretical foundation that supports and guides consistent and fair decision making (Masson, 2016). In this article we discuss the key principles that should inform decisions and good practice about contact for children in care.

\section{Background}

Contact between children in care and the individuals who are important in their lives, particularly family, has been defined as the intentional communication between children and others, and can take the form of either being 'direct' in the form of faceto-face meetings, or can be 'indirect' through letters, telephone, email and so forth. Particular activities, photographs and other mementos which remind children of home can also be construed as indirect contact (Cleaver, 2000). Direct contact can be unsupervised or supervised by social workers, foster carers, other professionals and sometimes family members and friends. 
Questions about the quality, frequency and type of contact remain a major consideration for families, social workers, guardians ad litem, legal practitioners and courts. Issues such as how much contact should occur and where and when this should take place are challenging for all involved (Bullen et al., 2015). Further issues that need to be addressed include the need for supervision and justifying why this is so are pertinent to decision making, alongside details of what activities are appropriate, and clearly setting out any specific requirements for contact in particularly complex family situations.

For children entering care, particularly when decisions are still to be made about the child's long term care arrangements, issues relating to the maintenance of family relationships will always be to the fore, as enshrined in human rights legislation. (Human Rights Act 1998; UNCRC 1989). As Humphreys \& Kiraly (2011, p.2) note, "striking the balance between the infant's need to develop a stable attachment relationship with a caregiver, while keeping alive the possibility of reunification through the maintenance of family relationships, is difficult territory that highlights the systems issues that create the context for contact".

For example, the literature on neuroscience and attachment draws attention to the first year of life as critical. During this year immense brain development occurs, and this is directly related to the infant's attachment experience (Howe, 2011). Particular significance lies in the need for secure attachment experiences with the person providing 24-hour care, usually assumed to be the primary carer, given the need to attune to the infant's highly visceral daily needs.

In a review of the research relating to contact for children in care Sen \& Broadhurst (2011) identified three claims for the importance of contact:

- prospects for reunification of children with birth family are increased;

- placements are less vulnerable to disruption; and,

- children's emotional, behavioural and intellectual development are increased.

While there are concerns sometimes expressed by carers that contact with birth families is disruptive and challenging for the child and their placement stability (Ainsworth \& Hansen, 2017), the evidence of a negative impact on placement stability is negligible, as highlighted in a recent Swedish study (Vinnerljung, Sallnas \& Berlin, 2017). However it has been shown that courts over-estimate the 
importance of high frequency contact between infants and birth families on the basis of improving the potential for reunification (Humphreys \& Kiraly, 2011). The current research base indicates that contact is a necessary, but not of itself a sufficient condition for reunification. This recognises the complex ways in which factors related to the child, birth family, placement family and services interact in determining the outcomes for children. Factors impacting positively on reunification in conjunction with contact are that children are not subject to legal orders, a strong attachment between child and mother is evident, there is no history of significant neglect, and children are not disabled. Where a parent's physical illness was the cause of admission to care, reunification is also more likely (Cleaver, 2000).

\section{The Assessment of Contact}

Although the law is clear in the United Kingdom and Ireland that there should be reasonable contact between birth families and children in state care, there is no simple or agreed formula for making decisions about what reasonable contact looks like (Children and Families Act 2014; Child Care Act 1991; The Children (Scotland) Act 1995; The Children (Northern Ireland) Order 1995). Triseliotis (2010) has also highlighted that neither is there explicit guidance for parents on what they should be saying or doing during contact, and no agreed guidelines for those supervising contact on how to assess what they are observing.

Increasingly contact is seen as a central part of the assessment process informing legal decision making about children (Atwool, 2013). Contact provides social workers with opportunities to directly observe family relationships and dynamics and screen for risk of abuse or trauma for some children (Selwyn, 2004). Furthermore, social workers can begin to assess parenting skills, and then help parents to improve those skills in a supported environment.

For many children contact frequently takes place on multiple occasions per week for significant periods of time. This is a unique opportunity, which commences immediately when a child is removed from their parent's care, and yet very often social workers can miss the opportunity to use contact productively to commence a parenting assessment and educative process with families. Thus, assessing contact may provide a good basis for assessing the potential viability of a return home for a 
child as well as serve as a process for getting the child home. An assessment of contact may therefore assist courts in reaching a determination about whether a child should remain in state care. However, given the evidence on judicial decision making, there is a need to ensure that courts are provided with clear, structured and unambiguous information about the needs of children and their parent's ability to provide for these needs (Masson, 2014).

Contact between children and their families takes up a significant amount of time for social workers and therefore it is important that these opportunities are used creatively in order to support decision making for children. Contact in itself will not provide all the information required but it is a good start and base from which to build upon.

\section{Supervised Contact}

In many cases, particularly those before the courts, contact between children and their family is supervised. Supervised contact, in its strict sense, refers to high vigilance contact in which interaction and conversation between the child and family member is closely monitored at a specialist contact service, in an office or in the community (Perry \& Rainey, 2007). Formal contact supervisors may either be there to purely observe and take notes about the interactions between the family member and child, while ensuring safety, or have a more engaged role that seeks to support and enhance interaction between the participants (Triseliotis, 2010).

In some instances parents may be provided with additional support during contact, particularly when there are concerns about their capacity to interact appropriately and sensitively with children (Perry \& Rainey, 2007; Sen \& Broadhurst, 2011). This may or may not be linked to assessment or reunification processes. However, it has been argued that there is a lack of an agreed understanding of the concept, definition, or purpose of supervised contact amongst legal and social work professionals working in the court arena (Wattenberg et al. 2011). This is compounded by the lack of an agreed framework for assessing the quality of contact, and a way of measuring, over time, whether children's needs are being met through contact with family members. This is particularly important whenever the courts are being asked to make decisions about whether a legal order should be made in 
respect of a child. Justifying the need for supervision is pertinent to decision making, as are details of what activities are appropriate and permitted during contact.

\section{Observation of Contact}

Whilst recognising that contact provides only a 'snapshot' of the interaction between a parent and child, and therefore is artificial in many respects, the reality is that this may be the social worker's only opportunity to have a closer look at the parent-child relationship when a child has been removed from a parent's care. Contact can provide the opportunity to begin to assess basic parenting skills and tasks, and also allow some observation of parent and child relationships, including how a parent relates to their child and indeed how the child relates to their parent, and how a parent copes when under stress, which is a natural part of everyday parenting (Tyler, 2011).

Throughout the United Kingdom and Ireland there is no agreed way to observe or record contact, therefore it is unlikely that two social workers will observe or describe contact in exactly the same way. Interpreting what is being observed may differ significantly between individuals depending on a number of things including professional role, theoretical perspective, background and experience, which will all shape an individual's interpretations (Devaney, Hayes \& Spratt, 2017).

Ideally several observations, completed by different social workers might be beneficial. Furthermore, observing contact over a full day, to include all of the normal stresses and strains that daily life brings to parenting could provide the optimum environment for assessment purposes. However, the reality for social workers is that contact sessions being observed and assessed for decision making purposes will likely be on average 1-2 hours in length.

Parents should have an opportunity to demonstrate their commitment to their child by attending contact promptly and coming well prepared. Through carefully planned and managed contact, the social worker should be able to assess not only a parent's current ability, but also their motivation to learn and willingness to accept and implement advice provided. 
According to Tyler (2011), relying on a parent's self-report or third party information when assessing the parent child-relationship is simply not enough. It is the direct observation of contact which will help establish what a parent can realistically do and whether they can put into practice what they say they can. Some parents can provide a good verbal account of their parenting skills however may struggle to put this into practice. For others, especially those with their own traumatic backgrounds, vulnerabilities or learning difficulties, being able to articulate how they care for their child may not be easy, however direct observation may demonstrate warm, sensitive parenting (Roberts, 2017). Parenting capabilities such as the ability to sooth a distressed child can only be assessed through direct observation (Tyler 2011). Arguably, social workers tend to use theory implicitly rather than explicitly (Avby, Nilsen \& Ellstrom, 2017). Although direct observation of contact is a fundamental part of assessment, it also needs to be informed by an understanding of theory and research. In other words, assessing contact goes further than simply collating information being recorded from contact visits. For example, an assessment of contact should draw upon our understanding of child development, attachment theory, psychotherapy, trauma and abuse, and parenting capacity, in order to make a holistic assessment of what is "good enough parenting" (Morris et al., 2017; Winnicott, 1988).

Alongside a child's need for safety, attachment between a child and their parent(s) is at the heart of robust decision making for children entering care (NICE, 2015). In this regard psychoanalytic observation makes an important contribution to the assessment of the parent-child relationship. Youell $(2005$, p.56) argues that "psychoanalytically informed observation can help social worker's and others to reflect on more than just the content of the play to examine the impact on them as observers and to use this as evidence in thinking about what may have been the child's experience". From this perspective the importance of focussing on the child during contact is highlighted, providing a framework for social workers to assess the meaning of children's behaviour and play which could be potentially very informative. Whilst direct observation, informed by theory is both an important and integral part of the overall assessment of contact, the framework being presented here goes further 
by also considering the voice of the child, the commitment and views of the parents as well as the important contribution from the child's carers.

\section{The Development of the Contact Assessment Framework}

The contact assessment framework began its development in 2003 when the first author was at that time directly involved in complex public law proceedings and identified what appeared to be a gap in an agreed assessment framework to inform decision making about contact. Decisions about the most appropriate level and frequency of contact between looked after children and their families was the subject of considerable debate and came under heavy scrutiny within the courts. Information about the details and quality of contact appeared to be largely gathered through voluminous contact records contained in children's files. Although a variety of observation recording proformas and checklists were available to social workers from a number of sources, there was no consistency in the use of same. Essentially there was no agreed framework for collating, recording or assessing what was happening during contact between children and their families which could be presented to the court. It was at that time that the first author, with the support of her organisation, began to develop the framework presented in this article with the purpose of providing social workers within one of the Health and Social Care Trusts in Northern Ireland (which have the same legal responsibilities for children in state care as local authorities in other parts of the UK) with an agreed framework which it was hoped would better inform decision making about contact, and one which social workers could present to the court.

Good practice guidance based on similar guidance found in local authorities in England was then adapted for use in Northern Ireland. International research, literature and good practice guidance were reviewed in order to inform the development of the assessment tools (Fahlberg, 2012; Lord \& Borthwick 2001; Mackaskill, 2002; Neil \& Howe, 2004; Slade, 2002).

Over the following years the assessment framework was implemented within one Trust. Constructive feedback, provided by a range of social workers using the assessment framework to assess contact provided the foundation for the updating of 
the tools. The framework was subsequently disseminated across all five Trust's in Northern Ireland through the Principal Social Work Practitioners for Court.

In 2011, the need for better consistency in terms of decision making about contact was highlighted at a joint seminar held between Health and Social Care Trusts and the Judiciary. Consequently, a working group was set up by the coordinator of the Children's Services Improvement Board (a standing committee of the Directors of Social Work in Northern Ireland for taking forward the strategic development of children's social care services) with the specific aim of producing regional guidance and an agreed assessment framework to support professional decision making and allow social workers to better inform family courts. The group membership was made up of social work practitioners (including the first author), managers and policy makers, and a senior member of the Judiciary.

What followed was the updating and then implementation of the existing regional guidance and assessment framework being used across the Trusts. The overarching aim has been to assist in the analysis of what is observed between parents and their children during contact and to provide a clear and consistent approach to assessing contact for children in care.

Included in the assessment framework are several sections:

- practice guidance to assist social workers in planning for contact;

- a contract agreement to be completed with parents clarifying details and expectations of contact. The details about the nature, frequency, times, days, venues and transport arrangements for all involved are therefore clarified;

- an observation sheet for collating observations of contact between children between the ages of 1-17 and their parents;

- the child's details including a weekly timetable of their routine and commitments;

- a separate observation sheet for recording interactions between babies under 1 year and their parents; and,

- an observation sheet to record observations of sibling contact;

There are also separate sections for recording:

- a summary of family background; 
- the views of all those involved in contact, namely the child, their parents and the child's carers;

- the parent's commitment to contact; and,

- the social worker's assessment and analysis of contact.

The framework has a number of underpinning principles:

- the child is at the centre of the assessment and his or her needs are paramount;

- parents should be seen as partners in the process of organising and facilitating contact;

- assessments need to be informed by an understanding of the quality of attachment relationships and developmental stages in children;

- foster carers and other carers should have an opportunity to contribute to the assessment, particularly in relation to children's presentation before and after contact; and,

- sibling relationships need to be maintained when children are placed separately.

Formal review and evaluation of the contact assessment framework has not as yet been completed and therefore is an important area for further development. In the next section we discuss in more detail the principles informing the framework.

\section{The child at the centre of the assessment}

The need to ensure that all contact arrangements are in the best interests of the child is what lies at the heart of this assessment framework. However in determining what contact arrangements are in child's best interests it will be important to consider a number of things including age and developmental stage, background history, the child's views and wishes, together with the views of their parents and indeed carers. Contact needs to be considered in the context of the child's overall well-being and care plan, while also recognising that contact takes place within the system around the child - their relationships with birth and placement families, and the social work and judicial systems. 
Achieving satisfaction with contact for all involves a delicate balance of a child's right to actively participate in decision-making about their contact with their right to be kept safe and have stability. However involving children and indeed their parents in decision making can lead to safety and stability over time if social workers take the time to build and maintain relationships with children and their families (Larkins et al., 2015).

Information and emotional support from workers has been found to be crucial in helping children get answers and come to terms with the information provided to them. Furthermore, practical support for children has been identified as important, including help with the practical arrangements, such as travel costs for parents, has been associated with children's satisfaction with contact arrangements (Larkins et al., 2015).

In a study by Sinclair et al. (2001) there was little uniformity in the type or frequency of contact that children in foster care wanted and not all children in foster care wanted contact, however they all did want to be consulted about contact arrangements.

Similarly, for some young people who had not had contact for some years, they valued opportunities to review and revise their decisions. Satisfaction has been associated with children and young people having influence over their contact and being consulted, supported and reminded that contact was their decision (Larkins et al, 2015).

Contact arrangements need to take account of not only the child's wishes but also reflect changes within their family circumstances (Department for Education, 2012). The need for regular review of contact is therefore explicit in the guidance.

Contact arrangements should also take account of the developing social world of the child and allow for things such as extra-curricular activities, school commitments, including homework, and children's friendships. Moyers et al. (2005) found that for some adolescents, sometimes having too much contact interfered with other activities. Transitions for children, for example to nursery for a young child or a new school with additional travelling for the child, place additional demands on children and contact may need to be adjusted to continue to meet the child's needs. 
The inclusion of the child's detailed weekly timetable within the assessment ensures that the child's routine and commitments remains at the centre of all contact plans.

The Practice Guidance on Assessing and Planning for Contact with Looked after Children (Northern Ireland Health and Social Care Board, 2012) highlights the need for flexibility around contact arrangements and the importance of regular review of arrangements, through the Looked After Child processes, in order to ensure that they continue to meet the child's changing needs.

The child's views are central to this assessment together with observations of their contact and feedback from the carers about the child's presentation and behaviour within the placement.

\section{Partnership with Parents}

Good preparation for parents as well as constructive feedback surely seems implicit when we fully consider 'promoting' contact. Ideally, the social worker should meet with the parent prior to commencement of the assessment and clarify expectations. This will be especially important where there may be concerns about a parent's negative attitude, either towards a child, their carer or the social worker. In such cases it is imperative that this is addressed appropriately with parents prior to contact taking place in order to protect children from same during contact. Similarly when a parent's attendance at contact is unreliable, this will likely have negative consequences for a child (Moyers et al., 2006).

Emotions typically run high for all family members when children are initially removed from parental care, even with parental agreement. The social work role therefore requires carefully and sensitively preparing parents and children for contact and then supporting and assisting parents with their parenting. This should involve explaining why contact is being planned in the way it is, what support is required, and clarity about any supervision or restrictions. Essentially what this means is taking the time to talk to parents about how they might use contact more productively, and in explaining how and what they are being assessed on. In other words, clarify what the workers will be looking for and expecting to see in contact and provide clear understandable feedback on a regular basis. Feedback should always be provided in 
order to help ensure a positive experience for parents and children and maximise the potential for educative work for parents.

The commitment and views of parents forms an integral part of this assessment framework. If a parent genuinely believes they are fully involved in the process this tends to work better than when they believe a plan is being imposed upon them. Parents want to be involved, to have information and to feel understood. They need empathy and respect from their social worker. If a parent genuinely believes they are being listened to this will likely promote better communication (Schofield \& Ward, 2011).

Contact agreements set out clear expectations of parents so there should be no ambiguity about what is expected of them during contact. This places a responsibility on the social worker to demonstrate what they are doing to assist parents and how they are proposing to do so. Contact agreements are therefore not only a way of including parents and carers in the process but also provide evidence to the court that everyone has been heard and consulted.

The practice guidance makes it clear that the focus should be to work cooperatively with families where possible and try to explain why certain arrangements are being proposed. There is recognition that sometimes this may be fraught with tensions and competing priorities (Atwool, 2013). The need to establish whether a parent can accept the contact arrangements being proposed is important. Although sadly not always achievable, contact is likely to work much better if simply not imposed on parents.

\section{The quality of children's attachment relationships and stages of development}

An understanding of attachment theories is invaluable for social workers trying to make sense of what they are observing between a child and his or her parent.

As Cooper highlights, Patricia Crittenden has warned social workers about the dangers of making assumptions based on appearances in child abuse cases, referring to the happy smiling faces of Victoria Climbie and Baby Peter as tragic examples where natural assumptions about the children being happy and smiling were really a learned defence mechanism (Cooper, 2010). 
It is important that contact is informed by child development and is child centred, taking account of the child's age and stage of development as well as their own history (Schofield \& Beek, 2006). Social workers need to understand the child's unique set of circumstances and what their particular experiences were previously in order to help make sense of what is observed during contact.

Background information and a summary of the child's life before they were removed from their parent's care forms an important part of any assessment of contact. Children's early experiences and their attachment relationships to parents before being placed in care will help inform how they will likely manage stressful situations, including contact.

Observing children with their parents during contact involves taking a closer look at the dynamics within their relationships, in essence, the attachment between them. The section for recording of observations draws on Fahlberg's 'Observation Checklist in Assessing Attachment and Bonding' (Fahlberg, 2012) as well as Coram's 'A Guide to Best Practice in Supervised Child Contact' (Slade, 2002).

\section{Foster carers' role in the assessment process}

The importance of considering the views and input from foster carers cannot be overstated. Foster carers have an important contribution to make to the assessment of contact and will have valuable information about how the child is doing overall. Foster carers may know children as well as anyone, including their wishes, concerns, strengths, routines, and unique characteristics. Foster carers are very often the ones who prepare the child for contact with their birth family, transport them to contact and then support them emotionally afterwards. They are also the ones left to 'pick up the pieces' when contact creates distress for the child (Ainsworth \& Hansen, 2017). Foster carers can provide important information about the child's presentation prior to and after contact and not just during contact. It is imperative that the time is taken to listen to what they have to tell us about the children they are caring for. Whilst not a specific requirement of the assessment, if it is possible for parents and foster carers to be supported to meet and discuss contact and share information, facilitated by the social worker. Positive relationships between foster and birth families are known to be beneficial for children in care (Beek \& Schofield 
2004). It is therefore important to identify appropriate support for foster carers and ensure this is provided to them.

If the goal is to ensure placement stability and avoid the distress and disruption of further placement moves for a child, then surely the foster carer needs to be heard in the assessment. The carer's own family routines need to be given consideration and indeed whether the contact proposals work for them and will support the placement (Schofield \& Beek 2006). It is important that this is not overlooked.

\section{The importance of sibling relationships}

In the United Kingdom legislation requires that siblings in care are placed together. (Children Act 1989; The Children (Scotland) Act 1995; The Children (Northern Ireland) Order 1995). However according to Ivaldi (2000) only $37 \%$ of looked after children are placed with their siblings. There are many differing reasons for this. Children in foster care tend to have complex and fragmented relationships compared to children who are not looked after. Nonetheless, sibling relationships are very often the longest and most enduring, significant relationships in our lifetime.

Rushton et al. (2001) found that children who had been rejected by a birth parent had better outcomes when placed with a sibling. For some children, sadly it is not always achievable, and in a minority of cases may not be desirable. Siblings are all too frequently separated from one another, sometimes with considerable distances between placements. The focus may remain on the childrens contact with their parents and not with one another. When siblings are placed separately from one another then effort needs to be made to ensure they maintain contact with one another.

Key questions about whether siblings should be placed together or whether they need to remain separate need to be addressed when children are removed from parental care. Guidance for assessing siblings in relation to permanent placement in "Together or Apart" (Lord \& Borthwick 2001) has largely informed the assessment of sibling contact in this framework. The authors highlight the need for a comprehensive assessment of siblings as a precursor to making decisions about siblings

placements. The increasing awareness of the impact of trauma on child development 
has been influential in informing our understanding of sibling relationships. Sibling contact provides an opportunity to look closely at the relationships between siblings and, it is hoped, consider what might be in their best interests. The assessment framework discussed here therefore may contribute to the overall assessment of whether siblings can remain together or need to be placed separately, and the frequency and nature of ongoing contact (Waid \& Wojciak, 2017).

\section{Discussion}

Debates about the removal of children into state care have traditionally centred on keeping children safe, maintaining stability in their placement, and providing them with a sense of being loved and cared for. More recently though there has been a growing recognition of children's need for their identity to be both recognised and promoted (Schofield, Larsson \& Ward, 2017). Contact plays a significant role in this respect, but there has been a surprising lack of discussion about how decisions should be arrived at, in spite of an increasing belief that contact is always beneficial, married with a perception that decisions made by the courts and through the looked after children review process about contact are often ad-hoc (Bullen et al. 2015).

There is a need to see contact as being multi-dimensional, both in terms of what it is seeking to achieve, but also in respect of whose interests are being served. In developing the framework presented in this article it is clear that contact is seeking to achieve a number of aims. Firstly, it is about maintaining the relationships between children in care and significant people in their live from before their admission to care, principally their birth family. Yet contact is also about informing decision making at particular points in time (such as whether children should come into care, remain in care or be returned to the care of a family member), and in ensuring that the State is enacting its legal obligations to both child and birth family. To date this second purpose has been more implicit than explicit, with the result that information about the nature and quality contact has been used to inform decision making, but in a largely unstructured way. This means that courts and the wider child care system are largely reliant on the expert opinion of individual professionals, with all of the challenges and pitfalls that this can bring (Hill, Welch \& Gadda, 2017; Masson 2016). There is therefore a need to ensure that decisions made about individual children are 
fair, proportionate and consistent. This requires that professionals are in agreement about the theoretical and research bases that should inform such decisions, and that there is a consistent approach to the gathering and interpretation of evidence in order to arrive at decisions that uphold the legal principle of being in the best interests on this child at this time, and promote empowering practice (Ruch et al. 2017). As such frameworks, such as the one described in this article, have the potential to strengthen decision making and give proper effect to the law.

However, there is also a need to avoid adopting a myopic interpretation of 'child centred practice'. While it is right that the courts and looked after children system make decisions that are child centred and seek to promote the best interests of children, it must be recognised that children exist within a series of systems and relationships that must co-operate in order to provide the opportunity for children to flourish (Featherstone, White \& Morris, 2014). As such, while discussions and decisions about the contact arrangements for children should be predicated upon the child's wishes and what is believed to be appropriate for the child, this cannot be done without appropriate engagement with other key actors, specifically the child's birth family and carers. Too often the views of birth parents and carers are sought, but not fully considered and incorporated into the decision making process (Boyle, 2017). This can result in frustration for these key people in the lives of children, and may undermine and frustrate the potential for child contact to be both an enjoyable experience for children, and beneficial in promoting placement stability and the long term plans for children, whether this is rehabilitation to the care of their birth family or some other form of permanent care. As Boyle's (2017) systematic review highlights, children are more likely to benefit from contact when carers have an open attitude towards contact and when birth family acceptance of the child's need to form an attachment to their carer is high. This requires that adults also have an opportunity for their needs in regards to contact to be both heard and acted upon, so that everyone feels their perspective has been considered and their needs addressed. This systemic approach to both understanding and facilitating contact requires a more nuanced approach to the process of decision making around child contact. 


\section{Conclusion}

If, as is widely accepted, it is the quality and not the quantity that should inform decision making about contact for children separated from their parents (Neil \& Howe, 2002), then surely the focus should be on ensuring that the quality of contact is the best we can achieve for children and their families.

Safe, enjoyable, quality contact does not just happen. A wide range of factors need to be considered and carefully balanced, together with planning and consultation with all those involved. In order to be able to determine what is good quality contact, robust assessment is key and lies at the heart of social work practice.

The need for some consistency around what that assessment involves is important if we are going to make evidenced based, transparent, fair, and sensible decisions for children and their families.

The framework outlined in this article asserts that an assessment of contact goes well beyond simply observing a child with their family during contact. If the underlying principle is to ensure that the child remains at the centre of this assessment process then the child has to be observed in the context of their overall circumstances and not simply the snapshot of contact. This includes observing how a child is in their foster placement in order to deepen our understanding of the child in the context of their world and add meaning to the assessment.

Whilst there is no agreed formula for making the right decisions about contact for any family, it is important that contact is assessed carefully and robustly and is inclusive of family and carers. Contact should never simply be imposed by courts without careful consideration of every child's own unique circumstances and without listening to all those involved in the contact arrangements for the child.

It is important to remember however that there is no 'one size fits all' approach to planning contact for children in state care, and plans that appear to work for a child at one stage, may need to be adjusted at a later date, thus highlighting the need for regular review. Flexibility is key and social workers need to have the confidence to be creative and try out different variations of contact in order to find what will work best for a child and adjust contact if it is simply not working. 
While the framework described has not, as yet, been evaluated, it has the potential to address Boyle's (2017) assertion that decision making in respect of contact needs to be more reflexive and grounded in a clear assessment of a child's needs and what others can provide to ensure that contact works. Above all though it requires highly skilled practitioners able to both facilitate constructive discussions between all of the key parties, and also undertake systemic observations that can be presented back to parents and carers, and decision makers to ensure that the aims of contact are realised in ways that ultimately meet the needs of children.

\section{Acknowledgements}

(To be inserted later) 


\section{References}

Ainsworth, F. \& Hansen, P. (2017). Understanding the Behaviour of Children in Care before and after Parental Contact. Children Australia, 42(1), 5-8.

Atwool, N. (2013). Birth family contact for children in care: How much? How often? Who with? Child Care in Practice, 19(2), 181-198.

Avby, G., Nilsen, P. \& Ellström, P. E. (2017). Knowledge use and learning in everyday social work practice: a study in child investigation work. Child \& Family Social Work, 22(S4), 51-61.

Beek, M. \& Schofield, G. (2004). Providing a secure base in long-term foster care. London: BAAF.

Berrick, J. D., Peckover, S., Pösö, T. \& Skivenes, M. (2015). The formalized framework for decision-making in child protection care orders: A cross-country analysis. Journal of European Social Policy, 25(4), 366-378.

Boyle, C. (2017). 'What is the impact of birth family contact on children in adoption and long-term foster care?' A systematic review. Child \& Family Social Work, 22(S1), 22-33.

Brophy, J. (2006). Child care proceedings under the Children Act 1989. London: Department for Constitutional Affairs.

Bullen, T., Taplin, S., Kertesz, M., Humphreys, C. \& McArthur, M. (2015). Literature review on supervised contact between children in out-of-home care and their parents. Canberra: Institute of Child Protection Studies, ACU.

Cafcass (2016) Care Demand Statistics. Available at: https://www.cafcass.gov.uk/leaflets-resources/organisational-material/care-andprivate-law-demand-statistics/care-demand-statistics.aspx

Cleaver, H. (2000). Fostering family contact. London: The Stationery Office.

Cooper, J. (2010). The importance of attachment theory for children's social workers. Community Care, $29^{\text {th }}$ November.

Department for Education (2012). Contact Arrangements for Children: A Call for Views. London: Department for Education. 
Department for Education (2016). Children looked after in England (including adoption) year ending 31 March 2016. London: Department for Education.

Devaney, J., Hayes, D. \& Spratt, T. (2017) The influences of training and experience in removal and reunification decisions involving children at risk of maltreatment:

Detecting a 'Beginner Dip'. British Journal of Social Work Advance Access

Fahlberg, V. I. (2012). A child's journey through placement. London, Jessica Kingsley Publishers.

Featherstone, B., White, S. \& Morris, K. (2014) Re-imaging Child Protection: Towards Humane Social Work with families. Bristol: Policy Press.

Fratter, J. (1996). Adoption with Contact: Implications for policy and practice. London: British Agencies for Adoption and Fostering.

Hill, M., Welch, V. \& Gadda, A. (2017). Contested views of expertise in children's care and permanence proceedings. Journal of Social Welfare and Family Law, 39(1), 42-66.

Howe, D. (2011). Attachment across the lifecourse: A brief introduction. London: Palgrave Macmillan.

Human Rights Act 1998

Humphreys, C. \& Kiraly, M. (2011) High-frequency family contact: a road to nowhere for infants. Child \& Family Social Work, 16(1): 1-11.

Ivaldi, G. (2000). Surviving Adoption. London: BAAF.

Kiraly, M. \& Humphreys, C. (2015). A tangled web: parental contact with children in kinship care. Child \& Family Social Work, 20(1), 106-115.

Larkins, C., Ridley, J., Farrelly, N., Austerberry, H., Bilson, A., Hussein, S., Manthorpe, J. \& Stanley, N. (2015) Children's, young people's and parents' perspectives on contact: Findings from the evaluation of social work practices. British Journal of Social Work, 45(1), 296-312.

Lord, J \& Bothwick, S. (2001). Together or Apart? Assessing Brothers and Sisters for Permanent Placement. London: BAAF. 
Lowe, N., Murch, M., Borkowski, M., Weaver, A., Beckford, V. \& Thomas, C. (1999). Supporting Adoption: Reframing the approach. London: BAAF.

Loxterkamp, L. (2009). Contact and truth: the unfolding predicament in adoption and fostering. Clinical Child Psychology and Psychiatry, 14(3), 423-435.

Macaskill, C. (2002.). Safe Contact? Children in permanent placement and contact with their birth relatives. Dorset: Russell House Publishing.

Masson, J. (2014). What's wrong with linear judgments? Family Law, 44(9), 12771283.

Masson, J. (2016). Relationships v Relatedness in family justice. Journal of Social Welfare and Family Law, 38(4), 456-459.

Morris, K., White, S., Doherty, P., \& Warwick, L. (2017). Out of time: theorizing family in social work practice. Child \& Family Social Work, 22(S3), 51-60.

Moyers, S., Farmer, E. \& Lipscombe, J. (2006). Contact with Family members and its impact on adolescents and foster placements. British Journal of Social Work, 36. 541-559.

National Audit Office (2014). Children in Care. HC 787. London: House of Commons. National Institute for Health and Care Excellence (2015). Looked After Children and Young People. Public health guideline [PH28]. London, NICE.

Northern Ireland Guardian ad Litem Agency (2016) Annual Statistics 2015-2016.

Available at: http://www.nigala.hscni.net/pdf/Annual Stats 2015-

2016 Final version.pdf

Neil, E. \& Howe, D. (2004). Contact in Adoption and Permanent Foster Care: Research, Theory and Practice. London: BAAF.

Perry, A. \& Rainey, B. (2007). Supervised, Supported and Indirect Contact Orders: Research Findings. International Journal of Law, Policy and the Family, 21(1), 21-47.

Rees, G. \& Stein, M. (2016) 'Children and young people in care and leaving care' in Bradshaw, J. (ed) The Well-Being of Children in the UK (Fourth Edition). Bristol: Policy Press. 
Roberts, L. (2017) A small-scale qualitative scoping study into the experiences of looked after children and care leavers who are parents in Wales. Child \& Family Social Work 22(3), 1274-1282.

Ruch, G., Winter, K., Cree, V., Hallett, S., Morrison, F. \& Hadfield, M. (2017). Making meaningful connections: using insights from social pedagogy in statutory child and family social work practice. Child \& Family Social Work, 22(2), 1015-1023.

Rushton, A., Dance, C., Quinton, D. \& Mayes, D. (2001) Siblings in Late Placements. London: BAAF

Schofield, G. \& Beek M. (2006) Attachment Handbook for foster care and adoption. London: BAAF.

Schofield, G. \& Ward, E. (2011) Understanding and working with parents of children in long-term foster care. London: Jessica Kingsley Publications

Schofield, G., Larsson, B. \& Ward, E. (2017). Risk, resilience and identity construction in the life narratives of young people leaving residential care. Child \& Family Social Work, 22(2), 782-791.

Sen, R. \& Broadhurst, K. (2011). Contact between children in out-of-home placements and their family and friends networks: a research review. Child \& Family Social Work, 16(3): 298-309.

Sinclair, I., Wilson, K. \& Gibbs, I. (2001). 'A life more ordinary': What children want from foster placements. Adoption \& Fostering, 25(4), 17-26.

Slade, A. (2002). A Guide to Best Practice in Supervised Child Contact. London: Coram.

Tyler, T. (2011) The Observation of Contact in Expert Assessments of Parenting Capacity: Is Your Client at a Disadvantage? Family Law July, 41(7), 719-723.

Triseliotis, J.H. (2010). Contact between looked after children and their parents: a level playing field. Adoption and Fostering, 14(3), 59-64.

United Nations Convention of the Rights of the Child 1989

Vinnerljung, B., Sallnäs, M. \& Berlin, M. (2017). Placement breakdowns in long-term foster care-a regional Swedish study. Child \& Family Social Work, 22(1), 15-25. 
Waid, J. \& Wojciak, A. S. (2017). Evaluation of a multi-site program designed to strengthen relational bonds for siblings separated by foster care. Evaluation and Program Planning, 64, 69-77.

Wattenberg, E., Troy, K. \& Beuch, A. (2011) Protective supervision: An inquiry into the relationship between child welfare and the court system. Children and Youth Services Review, 33(2), 346-350.

Winnicott, D.W.(1988). Babies and their Mothers. London: Free Association Books.

Youell, B. (2005). "Observation in social work practice." In Bower, M. (ed) Psychoanalytic Theory for Social Work Practice: Thinking under Fire. London: Routledge. 